\title{
FATORES DE RISCO ASSOCIADOS À INFECÇÃO POR Toxoplasma gondii EM GESTANTES ATENDIDAS EM UMA UNIDADE DE SAÚDE ESPECIALIZADA NO MUNICÍPIO DE CURITIBA-PARANÁ
}

\author{
(Risk factors to Toxoplasma gondii infection in pregnant women attend in a \\ specialized health unit in Curitiba-Paraná)
}

\author{
Pedro de Alcântara Brito Junior ${ }^{1}$, Ana Paula Coninck Mafra Poleto², Viviani Bontorin ${ }^{1}$, Vivien \\ Midori Morikawa ${ }^{3}$
}

\begin{abstract}
${ }^{1}$ Programa de Residência Multiprofissional em Saúde da Família - Universidade Federal do Paraná,
${ }^{2}$ Unidade de Vigilância de Zoonoses de Curitiba, ${ }^{3}$ Departamento de Saúde Coletiva - Universidade Federal do Paraná
\end{abstract}

Corresponding author: pedrobritojr@yahoo.com.br

RESUMO: O objetivo do presente estudo foi estimar a prevalência e identificar os possíveis fatores de risco associados à infecção por Toxoplasma gondii em 103 gestantes atendidas pelo Sistema Único de Saúde, em uma unidade de saúde especializada no município de Curitiba, Paraná. Para isso, foi realizado um estudo epidemiológico transversal quantitativo a partir da realização de entrevistas utilizando um questionário estruturado. As informações referentes à sorologia para T. gondii foram obtidas a partir das cadernetas das gestantes durante a entrevista. A investigação sorológica foi realizada por meio do ensaio imunoenzimático indireto e ensaio imunoenzimático de captura para identificação de $\lg$ e $\operatorname{lgM}$, respectivamente. Os testes do Qui Quadrado e Exato de Fischer foram utilizados para estimar a associação entre fatores de risco e sorologia. Anticorpos IgG e IgM foram detectados em 56,31\% (58/103) e 0,97\% (1/103), respectivamente. Houve associação estatisticamente significativa entre as variáveis renda familiar $(p=0,03)$, tipo de moradia ( $p=0,005$ ), consumo de carne crua ou malcozida e ingestão de frutas e vegetais mal higienizados $(p=0,045)$. Deste modo, a identificação de prováveis fatores de risco, poderá auxiliar na implantação de medidas de prevenção e controle da toxoplasmose materna e congênita.

Palavras-chave: Fonte de infecção; prevalência; toxoplasmose; transmissão vertical.

ABSTRACT: The objective of the present study was to estimate the prevalence and to identify the potential risk factors associated with Toxoplasma gondii infection in 103 pregnant women attended by the Unified Health System in a specialized health unit in the city of Curitiba, Paraná. For this, a quantitative cross-sectional epidemiological study was carried out based on interviews using a structured questionnaire. Information regarding serological screening was obtained from the pregnant women 's records during the interview. Serological investigation was performed by Indirect immunoenzymatic assay and capture immunoenzymatic assay for identification of IgG and IgM, respectively. The Chi-square and Fisher's exact test were used for data analysis, and the odds ratio (OR) was used to estimate the chance of association between exposure and outcome variables. IgG and IgM antibodies were detected in $56.31 \%(58 / 103)$ and $0.97 \%(1 / 103)$, respectively. There was a statistically significant association between the variables household income $(p$ $=0.03)$, type of housing $(p=0.005)$, consumption of raw or undercooked meat, and ingestion of poorly hygienized fruits and vegetables $(p=0.045)$. Thus, the identification of probable risk factors may assist in the implementation of prevention 
and control measures for maternal and congenital toxoplasmosis.

Keywords: Source of infection; prevalence, toxoplasmosis, vertical transmission. 


\section{INTRODUÇÃO}

A toxoplasmose é uma antropozoonose causada pelo protozoário intracelular obrigatório Toxoplasma gondii. É um parasita heteroxeno facultativo, tendo como hospedeiro definitivo os felideos, e como hospedeiro intermediário os animais homeotérmicos, incluindo o ser humano (Dubey, 2010). Devido a distribuição geográfica cosmopolita, pouca especificidade quanto aos hospedeiros e, capacidade de gerar abortos e doenças congênitas o $T$. gondii tem sido estudado intensamente ao longo do tempo (Tenter et al., 2000).

Todos estão susceptíveis à infecção por T. gondii por meio dos três estágios infectantes do protozoário. A transmissão ocorre através da ingestão de alimentos ou água contaminados com oocistos esporulados ou pelo consumo de carne crua ou malcozida contendo cistos do parasita, além da via vertical, pela transmissão transplacentária de taquizoítos (Guo et al., 2015). Transfusões de sangue e transplantes de órgãos também podem ser fontes de infecção (Dubey, 2008).

Estima-se que a toxoplasmose afete um terço da população mundial, mas a prevalência varia em diferentes populações de acordo com características geográficas, sociais e a exposição a fatores de risco como alimentos contaminados, qualidade da água e interações com animais (Moura et al., 2018; Amendoeira e CamilloCoura, 2010). No Brasil a taxa de infecção é considerada elevada em seres humanos, e, de acordo com Dubey et al. (2012), entre 50 e $80 \%$ das mulheres em idade fértil possuem anticorpos contra $T$. gondii. Os riscos para as mulheres brasileiras não infectadas adquirirem toxoplasmose durante a gravidez e ocorrer transmissão fetal são altos pois há ambientes altamente contaminados com oocistos (Dubey et al., 2012). A infecção geralmente é
assintomática imunocompetentes, sendo o grupo de risco a população com o sistema imunológico comprometido, como portadores do vírus da imunodeficiência humana (HIV), transplantados, indivíduos submetidos a terapias imunossupressoras e gestantes (Amendoeira e Camillo-Coura, 2010; Tenter et al., 2000). A vulnerabilidade das gestantes pode ser atribuída a alterações imunológicas e hormonais que ocorrem durante o período gestacional (Bittencourt et al., 2012). Nesse grupo, a infecção pode causar aborto, nascimento prematuro e comprometimento fetal como microcefalia, retinocoroidite, calcificações cerebrais e deficiência mental (Mitsuka-Breganó et al., 2010).

O curso da doença varia de acordo com a idade gestacional em que a soroconversão materna ocorre, com a cepa do parasita e da capacidade da resposta imunológica do hospedeiro. A probabilidade de transmissão ao feto durante a primo-infecção é de $25 \%$ no primeiro trimestre, $54 \%$ no segundo e $65 \%$ no terceiro trimestre (Amélia e Brod, 2008). A severidade da forma congênita vai depender da idade do feto, sendo a infecção no início da gestação geralmente associada ao aborto ou a sequelas mais severas, enquanto a infecção tardia, embora mais frequente, leva a sequelas menos severas (Amendoeira e Camillo-Coura, 2010).

No Brasil, estima-se que a toxoplasmose congênita afete de uma a 23 crianças a cada 10.000 nascidos vivos, variando de acordo com as características regionais (Dubey et al., 2012). Assim, o diagnóstico precoce é ferramenta fundamental na prevenção e controle da toxoplasmose gestacional e congênita.

A toxoplasmose aguda gestacional e congênita foram incluídas 
nas Lista de Notificação de Doenças e Agravos Compulsórios em Unidades Sentinelas a partir de agosto de 2010 (Brasil, 2010). No entanto, no Estado do Paraná essa notificação é compulsória desde 2003 como toxoplasmose não especificada, sendo que desde 2006, a Secretaria de Estado de Saúde do Paraná vem adotando ações programadas conforme as Diretrizes Clínicas, Laboratoriais e Terapêuticas da Toxoplasmose Congênita, documento aprovado na Comissão Intergestora Bipartite $n^{\circ}$ 72/06 (Paraná, 2006). O aprimoramento dessas ferramentas integradas com a atenção primária, especializada e hospitalar e demais serviços de saúde permitem a produção de informações epidemiológicas e ampliação sobre o conhecimento da doença no Brasil (Dario Capobiango et al., 2016; Brasil, 2018).

Assim, o objetivo do presente estudo foi verificar se há associação entre possíveis fatores de risco à infecção por $T$. gondii e dados sorológicos, além de determinar a ocorrência de anticorpos contra $T$. gondii em gestantes atendidas em uma unidade de saúde no município de Curitiba, Paraná.

\section{MATERIAL E MÉTODOS}

Foi realizado um estudo abordagem quantitativa na Unidade de Saúde Especializada Mãe Curitibana, serviço municipal de referência para pré-natal de alto risco da cidade de Curitiba, Paraná, no período de abril a setembro de 2018. Nesse serviço foram realizadas entrevistas a partir de um questionário estruturado validado e adaptado (LOPES et al., 2009) com gestantes que se encontravam na sala de espera e aceitaram participar da pesquisa de forma voluntária, após assinar o termo de consentimento livre e esclarecido (TCLE). Os critérios de inclusão abrangeram gestantes residentes do município de Curitiba, e que possuíam o registro da triagem sorológica para anticorpos IgG contra $T$. gondii em suas cadernetas de gestação.

O município de Curitiba conta com - Programa Mãe Curitibana, que preconiza, dentre outras ações, a realização de triagem sorológica para toxoplasmose em todas as gestantes na primeira consulta do pré-natal, além da sorologia trimestral nas grávidas consideradas suscetíveis (IgG e $\lg M$ negativas). $O$ diagnóstico é realizado pelo Laboratório Municipal de Curitiba, por meio do Ensaio Imunoenzimático Indireto (ELISA) e Ensaio Imunoenzimático de Captura (ELISA captura) para detecção de $\lg G$ e $\lg M$ contra $T$. gondii, respectivamente, além do teste de avidez de $\lg G$, realizado para determinar a época da infecção toxoplásmica (Curitiba, 2012). Essas informações sorológicas são registradas na carteira de pré-natal da gestante, de onde foi possível obter os dados sorológicos das participantes.

O questionário foi composto por 59 questões subdivididas em grupos com dados referentes às questões sociodemográficas, escolaridade, condições de moradia e saneamento, contato com solo, convívio com animais, hábitos higiênicos-alimentares e acerca do conhecimento da participante sobre a toxoplasmose. Ao término da entrevista, as participantes foram informadas sobre as formas de transmissão e medidas de prevenção da toxoplasmose por meio de um material informativo.

O tamanho amostral foi estimado de acordo com a média mensal de atendimento na Unidade de Saúde (3.000 consultas), considerando-se taxa de prevalência de $50 \%$, erro padrão de $10 \%$ e nível de confiança de $95 \%$, resultando em 94 gestantes (Dean et al., 2006). Considerando a chance de erro amostral, foi acrescido $10 \%$ a este valor 
totalizando o mínimo de 103 participantes.

A associação entre a variável dependente IgG contra $T$. gondii reagente e as variáveis independentes contidas no questionário epidemiológico foram avaliadas pelos testes estatísticos Qui-quadrado, com correção de Yates, e Exato de Fisher com intervalos de confiança de 95\%. Além disso, foi calculado a Razão de Chances (odds ratio) para avaliar a força de associação entre os fatores de risco e a sorologia. Todas as análises estatísticas foram realizadas no software Epi Info ${ }^{\mathrm{TM}}$ 7.2.0.1
(Center for Diseases Control and Prevention, USA). Para elaboração do mapa foi utilizado o software Quantum GIS versão 2.18 (QGIS Development Team, 2018).

\section{RESULTADOS}

Foram realizadas 103 entrevistas com gestantes residentes de 41 bairros da cidade de Curitiba, caracterizando uma amostra representativa dos dez distritos sanitários do município, como pode ser observado na Figura 01.

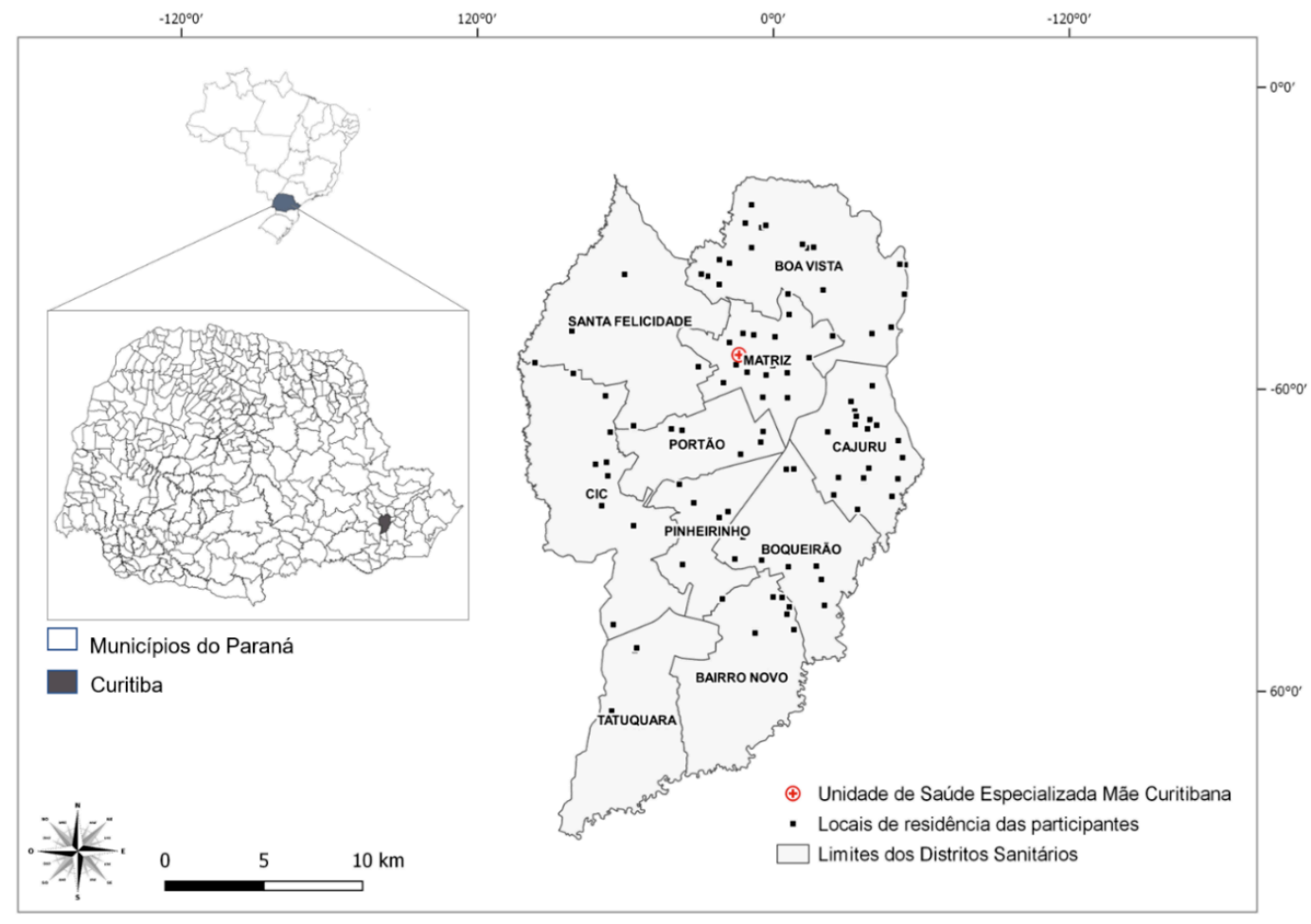

Figura 1 - Mapa da distribuição espacial dos locais de residência das participantes da pesquisa, de acordo com os Distritos Sanitários do município de Curitiba - PR, 2018.

Em 88,35\% (91/103; IC 95\%: 80,53 - 98,83) das participantes foi realizada a triagem sorológica para $\lg G$ e IgM contra $T$. gondii no primeiro trimestre gestacional, 9,71\% (10/103; IC $95 \%: 4,75-17,13)$ no segundo e $1,94 \%$ (2/103; IC 95\%: 0,24 - 6,84) no terceiro trimestre de gestação, pela Secretaria Municipal de Saúde de Curitiba.
A soroprevalência de anticorpos IgG contra $T$. gondii entre as gestantes foi de 57,28\% (59/103; IC 95\%: 47,15 $66,98)$, sendo que destas apenas uma (IC 95\%: 1,03 - 61,86) apresentou anticorpos IgG e IgM reagentes. Esta participante foi submetida ao teste de avidez de IgG no primeiro trimestre da gestação, apresentando forte avidez, indicando infecção crônica. Nenhuma 
participante apresentou apenas anticorpo IgM positivo (Tabela 01).

A idade das participantes variou entre 17 e 39 anos com média de 27,8 anos $( \pm 6,2)$ com faixa etária predominante de 20 a 29 anos $(49,51 \%$;
IC 95\%: 39,51 - 59,54). Ademais, detectou-se 0 aumento da soroprevalência de acordo com o aumento da faixa etária (Tabela 2).

Tabela 1 - Frequência de $\lg$ e IgM contra Toxoplasma gondii em gestantes do município de Curitiba - PR, 2018.

\begin{tabular}{lccc}
\hline Anticorpos contra Toxoplama gondii & $\mathbf{n}^{\circ}$ & $\%$ & IC 95\% \\
\hline Soropositividade & & & \\
IgG (+); IgM (-) & 58 & 98.30 & $60,82-50,39$ \\
IgG (+); IgM (+) & 1 & 1,7 & $1,03-61,86$ \\
\hline Total soropositividade & $\mathbf{5 9}$ & $\mathbf{5 7 , 2 8 \%}$ & $47,15-66,98$ \\
\hline Suscetibilidade & & & \\
IgG (-); IgM (-) & $\mathbf{4 4}$ & $\mathbf{4 2 , 7 2 \%}$ & $33,02-52,85$ \\
\hline Total de amostras & 103 & 100 & \\
\hline
\end{tabular}

Tabela 2 - Soroprevalência de IgG e IgM contra Toxoplasma gondii em gestantes do município de Curitiba - PR, de acordo com a faixa etária, 2018.

\begin{tabular}{ccc}
\hline \multirow{2}{*}{ Faixa etária } & \multicolumn{2}{c}{ Anticorpos contra T. gondii } \\
\cline { 2 - 3 } & \% (Positiva/Total) & \% (Negativa/Total) \\
\hline$<20$ & $54,55(6 / 11)$ & $45,45(5 / 11)$ \\
$20-29$ & $56,86(29 / 51)$ & $43,14(22 / 51)$ \\
$30-39$ & $58,54(24 / 41)$ & $41,46(17 / 41)$ \\
\hline
\end{tabular}

Em relação a fase gestacional das entrevistadas, $51,46 \% \quad(53 / 103)$ encontravam-se no segundo trimestre de gestação (de 14 a 26 semanas), $31,07 \%$ (32/103) no terceiro (de 27 a 40 semanas) e $17,48 \%$ (18/103) no primeiro trimestre (de um a 13 semanas).

A análise bivariada das características sociodemográficas e obstétricas com o resultado sorológico mostrou associação estatisticamente significativa das variáveis renda familiar ( $p=0,035)$ e tipo de moradia $(p=0,005)$ com a presença de anticorpos lgG. Gestantes com até um salário mínimo de renda familiar apresentaram risco 3,5 vezes mais elevado de se infectarem pelo $T$. gondii do que as demais (Tabela 3). O intervalo da faixa etária utilizado na análise bivariada foi dividido de acordo com a média das idades $(27,8$ anos).
Com relação aos hábitos higiênicos - alimentares houve associação entre sorologia positiva para IgG contra $T$. gondii com o consumo de frutas e verduras com higienização inadequada $(p=0,045)$ e consumo de carne crua ou malcozida ( $p=0,0456$ ), como pode ser observado na tabela 4.

\section{DISCUSSÃO}

A prevalência mundial da toxoplasmose tem grande amplitude, podendo variar de 20 a $90 \%$ na população humana. Em mulheres em idade fértil, esse índice oscila entre 4 e $85 \%$, dependendo das características geográficas, climáticas, culturais e da exposição aos fatores de risco (Tenter 2000; Amendoeira e Camillo-Coura, 2010). No Brasil, inquéritos sorológicos revelam uma alta soroprevalência em 
mulheres grávidas podendo variar entre

36-92\% (Dubey et al., 2012).

Tabela 3 - Características sociodemográficas e obstétricas associadas à soropositividade de IgG contra Toxoplasma gondii em gestantes do município de Curitiba - PR, 2018.

\begin{tabular}{|c|c|c|c|c|}
\hline \multirow{2}{*}{ Variáveis } & \multicolumn{2}{|c|}{ Anticorpos contra T.gondii } & \multirow[b]{2}{*}{$\mathrm{OR}^{1}\left(\mathrm{IC}^{2} 95 \%\right)$} & \multirow[b]{2}{*}{$\begin{array}{l}\text { Valor } \\
\text { de } p\end{array}$} \\
\hline & $\%$ (Positivas/Total) & $\%$ (Negativas/Total) & & \\
\hline \multicolumn{5}{|l|}{ Faixa etária } \\
\hline$\leq 27$ anos & $52,94(27 / 51)$ & $47,05(24 / 51)$ & \multirow{2}{*}{$0,70(0,32-1,54)$} & \multirow{2}{*}{0,49} \\
\hline$>27$ anos & $61,53(32 / 52)$ & $38,46(20 / 52)$ & & \\
\hline \multicolumn{5}{|l|}{$N^{\circ}$ de gestações } \\
\hline Primigesta & $53,70(29 / 54)$ & $46,29(25 / 54)$ & \multirow{2}{*}{$0,73(0,33-1,61)$} & \multirow{2}{*}{0,56} \\
\hline Multigesta & $61,22(30 / 49)$ & $38,77(19 / 49)$ & & \\
\hline \multicolumn{5}{|l|}{ Escolaridade (anos) } \\
\hline$\leq 8$ anos & $58,82(10 / 17)$ & $41,17(7 / 17)$ & \multirow{2}{*}{$1,07(0,3752-3,10)$} & \multirow{2}{*}{0,89} \\
\hline$>8$ anos & $56,97(49 / 86)$ & $43,02(37 / 86)$ & & \\
\hline \multicolumn{5}{|l|}{ Renda familiar } \\
\hline$\leq$ Um salário mínimo ${ }^{3}$ & $76,19(16 / 21)$ & $23,80(5 / 21)$ & \multirow{2}{*}{$3,52(1,18-10,53)$} & \multirow{2}{*}{0,035} \\
\hline > Um salário mínimo & $47,56(39 / 82)$ & $52,43(43 / 82)$ & & \\
\hline \multicolumn{5}{|l|}{ Tipo de moradia } \\
\hline Casa com jardim/quintal & $41,66(20 / 48)$ & $58,33(28 / 48)$ & \multirow{2}{*}{$0,293(0,12-0,66)$} & \multirow{2}{*}{0,005} \\
\hline Casa sem jardim/quintal & $70,90(39 / 55)$ & $29,09(16 / 55)$ & & \\
\hline \multicolumn{5}{|l|}{ Histórico de aborto } \\
\hline Sim & $57,14(8 / 14)$ & $42,85(6 / 14)$ & \multirow{2}{*}{$0,99(0,31-3,10)$} & \multirow{2}{*}{0,78} \\
\hline Não & $57,30(51 / 89)$ & $42,69(38 / 89)$ & & \\
\hline
\end{tabular}

${ }^{1}$ Odds Ratio; ${ }^{2} \mathrm{C}$ : Intervalo de Confiança; ${ }^{3}$ Equivalente a R $\$ 945,00$

No presente trabalho, a ocorrência de IgG contra $T$. gondii em gestantes foi de $57,28 \%(59 / 103$; IC 95\%: 47,15 - 66,98), resultado semelhante ao encontrado em pesquisas realizadas no estado de São Paulo por Galisteu et al. (2007) e por Isabel et al. (2007), em que a soroprevalência de anticorpos $\operatorname{lgG}$ contra $T$. gondii foi de $57,3 \%$ e $58,0 \%$, respectivamente. No entanto, um estudo transversal retrospectivo realizado em Curitiba a partir dos resultados emitidos pelo Laboratório Municipal entre 2010 e 2014 revelou menor soropositividade $(28,9 \%)$ (Santos et al., 2017). Porém, estes dados não podem ser diretamente comparados devido à variação metodológica da pesquisa empregada. No Paraná, os índices de prevalência corroboram com os resultados encontrados neste trabalho, como
$57,2 \%$ no Oeste do estado, $55 \%$ em Rolândia, 59,8\% em Palotina e 49,2\% em Londrina (Lopes et al., 2009; Dias et al., 2011; Nesi et al., 2013; Muller e Torquetti, 2017;).

A frequência de gestantes soronegativas foi de $42,72 \%$ (44/103; IC 95\%: $33,02 \quad$ - 52,85), essa suscetibilidade possibilita a ocorrência da infecção aguda durante o período gestacional, com o risco da transmissão vertical. Neste grupo, principalmente, é importante proceder o acompanhamento sorológico trimestral e intensificar medidas de prevenção primária com o objetivo de evitar a soroconversão durante a gestação. Estudos revelam taxa de soroconversão de $8,6 \%$ em grávidas de Goiânia, onde as gestantes apresentaram 2,2 vezes maior risco de conversão do que as mulheres não grávidas (Avelino et al., 2003). 
Tabela 4. Características higiênico-alimentares associadas à soropositividade de lgG contra Toxoplasma gondii em gestantes do município de Curitiba - PR, 2018.

\begin{tabular}{|c|c|c|c|c|}
\hline \multirow{2}{*}{ Fatores de risco } & \multicolumn{2}{|c|}{ Anticorpos contra T. gondii } & \multirow[b]{2}{*}{ OR (IC 95\%) } & \multirow[b]{2}{*}{$\begin{array}{l}\text { Valor } \\
\text { de p }\end{array}$} \\
\hline & \% (Positiva/Total) & $\%$ (Negativa/Total) & & \\
\hline \multicolumn{5}{|l|}{ Contato direto com solo } \\
\hline Sim & $73,33(11 / 15)$ & $26,66(4 / 15)$ & \multirow{2}{*}{$2,29(0,67-7,75)$} & \multirow{2}{*}{0,28} \\
\hline Não & $54,54(48 / 88)$ & $45,45(40 / 88)$ & & \\
\hline \multicolumn{5}{|l|}{ Ingestão de água tratada } \\
\hline Sim & $56,43(57 / 101)$ & $43,56(44 / 101)$ & \multirow{2}{*}{$0(0,0-4,64)$} & \multirow{2}{*}{0,65} \\
\hline Não & $100(2 / 2)$ & $0(0 / 2)$ & & \\
\hline \multicolumn{5}{|l|}{ Convívio com gatos } \\
\hline Sim & $46,66(21 / 45)$ & $53,33(24 / 45)$ & \multirow{2}{*}{$0,46(0,20-1,02)$} & \multirow{2}{*}{0,08} \\
\hline Não & $65,51(38 / 58)$ & $34,48(20 / 58)$ & & \\
\hline \multicolumn{5}{|c|}{ Contato com fezes de gatos } \\
\hline Sim & $100(3 / 3)$ & $0(0 / 3)$ & \multirow{2}{*}{ indefinido } & \multirow{2}{*}{0,35} \\
\hline $\begin{array}{l}\text { Não } \\
\text { Consumo de vegetais c } \\
\text { ( } \geq 1 \mathrm{vez} \text { / semana) }\end{array}$ & $56(56 / 100)$ & $44(44 / 100)$ & & \\
\hline $\operatorname{Sim}$ & $60(54 / 90)$ & $40(36 / 90)$ & \multirow{2}{*}{$2,4(0,72-7,92)$} & \multirow{2}{*}{0,24} \\
\hline Não & $38,46(5 / 13)$ & $61,53(8 / 13)$ & & \\
\hline \multicolumn{5}{|c|}{$\begin{array}{l}\text { Consumo de frutas e verduras com } \\
\text { higienização inadequada }\end{array}$} \\
\hline Sim & $\begin{array}{l}33,33 \\
(6 / 18) \\
62,35\end{array}$ & $66,66(12 / 18)$ & \multirow[t]{3}{*}{$0,30(0,10-0,88)$} & \multirow[t]{2}{*}{0,045} \\
\hline Não & $(53 / 85)$ & $37,64(32 / 85)$ & & \\
\hline \multicolumn{4}{|c|}{$\begin{array}{l}\text { Consumo de carne crua ou } \\
\text { malcozida }\end{array}$} & \\
\hline (1) & $\begin{array}{c}68,75 \\
(33 / 48) \\
47,27\end{array}$ & $31,25(15 / 48)$ & \multirow[t]{2}{*}{$2,45(1,09-5,50)$} & \multirow[t]{2}{*}{0,045} \\
\hline \multicolumn{3}{|c|}{$\begin{array}{l}\text { Consumo de leite cru ou não } \\
\text { pasteurizado }\end{array}$} & & \\
\hline $\operatorname{Sim}$ & $\begin{array}{l}0(0 / 2) \\
58,41\end{array}$ & $100(2 / 2)$ & \multirow[t]{2}{*}{$0(0,0-2.57)$} & \multirow[t]{2}{*}{0,36} \\
\hline Não & $(59 / 101)$ & $95,45(42 / 44)$ & & \\
\hline \multicolumn{5}{|c|}{ Presença de horta na residência } \\
\hline (3) & $\begin{array}{c}46,42 \\
(13 / 28) \\
61,33\end{array}$ & $53,57(15 / 28)$ & \multirow[t]{2}{*}{$0,54(0,22-1,31)$} & 0,25 \\
\hline \multicolumn{4}{|c|}{$\begin{array}{l}\text { Recebeu orientações sobre } \\
\text { prevenção da Toxoplasmose }\end{array}$} & \\
\hline 3 & $\begin{array}{c}56,45 \\
(35 / 62) \\
58,53\end{array}$ & $43,54(27 / 62)$ & \multirow[t]{2}{*}{$0,91(0,41-2,04)$} & 0,99 \\
\hline Não & $(24 / 41)$ & $36,17(17 / 41)$ & & \\
\hline
\end{tabular}

OR: Odds Ratio; IC: Intervalo de confiança.

A vulnerabilidade das gestantes ao parasita é provavelmente devido a alterações nos mecanismos imunes inerentes à gestação, resultante da supressão da resposta imune devido à necessidade de tolerância ao feto como 
consequência dos desequilíbrios hormonais característicos da condição gestacional (Bittencourt et al., 2012)

No presente estudo, apenas uma participante $\quad(1,7 \%) \quad$ apresentou anticorpos $\lg$ e $\lg \mathrm{M}$ contra $T$. gondii, resultado semelhante ao encontrado por Lopes et al. (2009) e Nascimento et al. (2002) no Paraná (1,2\%) e Bahia $(1,19 \%)$, respectivamente, e menor do que a observada em Tocantins por Gontijo da Silva et al., em 2015 ( $5,33 \%$ ). A presença de anticorpos IgM acompanhados dos anticorpos IgG não caracteriza uma infecção aguda, pois o IgM pode permanecer reagente por 18 meses ou mais após a infecção, denominados IgM residuais (MitsukaBreganó et al., 2010). Nesses casos é realizado o teste de avidez de IgG, que mede o grau de afinidade dos anticorpos com o antígeno. Uma fraca avidez destes anticorpos caracteriza uma infecção aguda, pois anticorpos IgG de baixa afinidade são produzidos no início da resposta imune primária, evidenciando uma infecção recente, num período inferior a quatro meses. Deste modo, à medida que a resposta imunológica ocorre, os anticorpos da classe IgG apresentam maior avidez, caracterizando uma infecção crônica (Detanico e Basso, 2006).

A triagem sorológica é uma medida de prevenção secundária, que permite a detecção da infecção e o tratamento precoce. Nesse estudo, grande parcela das gestantes $(88,35 \%$; IC 95\%: 80,53 - 98,83) foram triadas no primeiro trimestre gestacional, como preconizado pelo Ministério da Saúde (Brasil, 2018). Esse resultado permite avaliar 0 acesso e a qualidade do serviço de assistência pré-natal oferecido pelo município de Curitiba a partir do Programa Mãe Curitibana.

$\mathrm{Em}$ relação a idade, foi observada maior prevalência de anticorpos lgG contra $T$. gondii com o aumento da faixa etária. Este resultado já era esperado e corrobora com pesquisas realizadas por Sroka et al. (2010), Amélia et al. (2011), e Sartori et al. (2011) em estudos realizados em Fortaleza, Pelotas e Goiânia, respectivamente. Isso pode ser explicado pelo aumento da exposição às fontes de infecção ao longo da vida (Dubey, 2010).

Gestantes com baixa renda per capita, menor que um salário mínimo (< $\mathrm{R} \$ 945,00)$ apresentaram maior risco de infecção pelo $T$. gondii $(p=0,035)$. A prevalência de infecção por $T$. gondii tem sido associada ao status socioeconômico em vários estudos. Em Fortaleza, gestantes com baixa renda mensal tem 1,49 mais chances de se infectar do que aquelas com maior renda familiar (Sroka et al., 2010), resultado semelhante relatado por Dias et al.(2011) em Rolândia e por Lopes et al. (2009) em Londrina, ambos municípios do estado do Paraná.

A associação entre a vulnerabilidade econômica e condições de saúde de mulheres grávidas foi encontrada por Xavier et al. (2013) em estudo realizado no Rio de Janeiro, onde a baixa renda familiar esteve associado a malformações fetais, gravidez antes dos 15 anos e HIV. Esses achados enfatizam a importância de estratégias mais amplas de acesso e utilização de serviços de saúde, além de programas de redução da pobreza.

Outro fator que demonstrou associação significativa com a presença de anticorpos contra $T$. gondii foi o tipo de moradia ( $p=0,005)$, sendo a ausência de jardim e/ou quintal na residência considerada um fator de proteção contra a infecção (OR = 0,293; IC 95\%: 0,12 - 0,66). Este resultado pode ser explicado pela possibilidade de infecção por meio do contato com solo contaminado com oocistos, a partir de atividades como a jardinagem, por exemplo, fato evidenciado por um estudo conduzido em diversas regiões 
do mundo que isolou oocistos de $T$. gondii de amostras de solo (Tenter et al., 2000). Além disso, oocistos podem ser disseminados por meio de vetores mecânicos como minhocas e invertebrados coprófagos (Dubey, 2010).

A ingestão de carne crua e/ou malcozida foi um hábito frequente na população analisada, sendo que $46,6 \%$ (48/103) das entrevistadas possuíam este hábito, um fator de risco estatisticamente significativo $(p=0,045)$ para a presença de lgG contra $T$. gondii. A ingestão da carne crua e/ou malcozida apresentou um risco de 2,45 vezes maior do que àquelas que não possuem esse hábito. É um fator de risco importante pois pode ocorrer a transmissão de $T$. gondii a partir da ingestão dos cistos teciduais do parasita presente na carne (Guo et al., 2015).

Outra fonte alimentar importante na epidemiologia da infecção da toxoplasmose é por meio da ingestão de oocistos presentes na água ou alimentos. O consumo de frutas e vegetais crus não apresentou associação com o resultado sorológico, entretanto, a higienização inadequada desses alimentos foi estatisticamente significativa $(p=0,045)$. Um estudo realizado por Sroka et al. (2010) também identificou a ingestão de vegetais mal higienizados ou elaborados com água não tratada como fator de risco para soropositividade em gestantes no Nordeste. De acordo com Tenter et al. (2009), a transmissão da toxoplasmose em seres humanos é influenciada não apenas pelo potencial de contaminação de várias fontes alimentares, mas também pelo comportamento individual de consumidores em diferentes grupos étnicos e regiões geográficas.

Não foi constatada a associação entre a infecção por $T$. gondii e o convívio com gatos $(p>0,05)$, resultado semelhante ao encontrado por Amélia (2008) em Pelotas, Rio Grande do Sul, e por Jones (2001) em trabalho de soroprevalência e fatores de risco no Estados Unidos. No entanto, esse resultado difere do observado por Avelino et al. (2004) e Lopes et al. (2009), onde essa associação foi significativa. Porém, os autores afirmam que o simples fato de ter um gato no domicílio, não é suficiente para aumentar o risco de adquirir uma infecção por $T$. gondii. $O$ risco de infecção poderá existir somente quando ocorrer o contato direto com as fezes dos gatos que estejam eliminando oocistos. Esse risco é baixo pois a excreção de oocistos pelos felinos ocorre geralmente apenas uma vez na vida e duram poucas semanas (Dubey, 2010). No entanto, o risco existe, pois estudos demonstram o rederramamento de oocisros por gatos experimentalmente reinfectados e após aplicação de terapia imunossupressora (Zulpo et al., 2018; Malmasi et al., 2009). Deste modo, aos tutores de gatos é importante informar as medidas de prevenção da toxoplasmose felina que se baseia em não alimentá-los com carnes cruas ou malcozidas, remover suas fezes diariamente, evitar o acesso à rua e impedi-los de caçar (MitsukaBreganó et al., 2010).

Fornecer informações às gestantes sobre a prevenção da toxoplasmose é uma ferramenta primordial na prevenção dessa enfermidade, principalmente para as mulheres suscetíveis. Porém, 72,81\% $(75 / 103)$ das participantes não haviam sido informadas sobre medidas de prevenção, sendo $38,15 \% \quad(29 / 75)$ suscetíveis. A implantação de programas de educação em saúde deve ser realizada nesses casos. Há relatos que programas educacionais, além de reduzir o risco da infecção materna primária, permitem a redução da soroconversão durante a gestação (Tenter et al., 2000). Neste sentido, se faz necessária a educação permanente em saúde, sendo importante que 
profissionais da saúde obtenham qualificação adequada sobre toxoplasmose, com ênfase especial sobre a correta interpretação dos testes sorológicos, modos de transmissão de T. gondii e medidas preventivas, de modo a melhorar a qualidade do prénatal. Erros de interpretação de resultados sorológicos pelos profissionais de saúde e desconhecimento dos protocolos de tratamento podem ser prejudiciais à prevenção secundária, que consiste na detecção precoce e tratamento da toxoplasmose durante a gravidez (De Moura et al., 2017). Ademais, informação de saúde e estratégias de promoção da saúde podem ser relevantes para o público em geral como para as mulheres grávidas.

\section{CONCLUSÃO}

Os fatores de risco para toxoplasmose variam de acordo com a localização geográfica, diferenças climáticas, hábitos de alimentação e higiene da população e desenvolvimento socioeconômico local. Deste modo, a identificação dos fatores de risco regionais se faz necessária para o desenvolvimento de estratégias de prevenção e estabelecimento de programas de vigilância e controle da toxoplasmose materna e congênita.

Os resultados aqui apresentados enfatizam a importância da realização periódica da triagem sorológica durante o pré-natal, e do fornecimento de informações sobre medidas de prevenção à infecção, a fim de prevenir a ocorrência da toxoplasmose congênita. Foco específico deve ser dedicado em populações com acentuada diferença no nível socioeconômico, em populações que consomem carne crua ou malcozida e alimentos mal higienizados, pois apresentam maior risco de adquirir toxoplasmose.

\section{NOTAS INFORMATIVAS}

Este trabalho foi aprovado pelo comitê de ética em pesquisa da Secretaria Municipal de Saúde de Curitiba, sob o parecer consubstanciado de número 2.439.612.

\section{REFERÊNCIAS}

AVELINO, M.M.; CAMPOS, D. JR.; DO CARMO BARBOSA DE PARADA J. et al. Pregnancy as a risk factor for acute toxoplasmosis

seroconversion.

European journal of obstetrics, gynecology, and reproductive biology, v.108, n.1, p.19-24, 2003.

BITTENCOURT, L.H.F.B.; LOPESMORI, F.M.R.; MITSUKA-BREGANÓ, R. et al. Soroepidemiologia da toxoplasmose em gestantes a partir da implantação do Programa de Vigilância da Toxoplasmose Adquirida e Congênita em municípios da região oeste do Paraná. Revista Brasileira de Ginecologia e Obstetrícia, v. 34, n. 2, p. 63-68, 2012.

BRASIL. Ministério da Saúde. Portaria $\mathrm{n}^{\circ}$ 2.472, de 31 de agosto de 2010. Brasília, DF, 2010.

BRASIL. Ministério da Saúde. Secretaria de Vigilância em Saúde. Departamento de Vigilância das Doenças Transmissíveis. Protocolo de Notificação e Investigação: Toxoplasmose gestacional e congênita. Brasília, DF, 2018.

CAPOBIANGO, J.D.; MITSUKABREGANÓ, R.; LOPES-MORI, F.M.R. et al. Toxoplasmose adquirida na gestação e toxoplasmose congênita: uma abordagem prática na notificação da doença. Epidemiologia e Serviços de Saúde, v. 25, n.1, p.1-10, 2016.

Centers for Disease Control and Prevention. Epi Info [computer program]. 2002. Disponível em: 
https://wwwn.cdc.gov/epiinfo/html/prevv ersion.htm.

DE MOURA, F.L.; MILLAR, P.R.; FONSECA, A.B.M. et al. Congenital toxoplasmosis: perception of knowledge and primary prevention measures among healthcare professionals and pregnant women treated in public healthcare facilities. Scientia Medica, v.27, n.1, 2017.

DEAN, A.G.; SULLIVAN, K.M.; SOE, M.M. OpenEpi: Open Source Epidemiologic Statistics for Public Health [computer program]. Disponível em: www.openepi.com.

DETANICO, L; BASSO, R.M.C. Toxoplasmosis: serological profile of childbearing age and pregnant women Toxoplasmose: perfil sorológico de mulheres em idade fértil e gestantes Toxoplasmosis: serological profile of childbearing age and pregnant women.

Revista Brasileira de Analises Clinicas (Rio de Janeiro), v.38, n.1, p.15-18, 2006.

DIAS, R.C.F.; LOPES-MORI, F.M.R.; MITSUKA-BREGANÓ, R. et al. Fatores associados à infecção por Toxoplasma gondii em gestantes atendidas nas Unidades Básicas de Saúde do Município de Rolândia, Paraná, Brasil. Revista do Instituto de Medicina Tropical de Sao Paulo, v. 53, n.4, p.185-191, 2011.

DUBEY, J.P.; LAGO, E.G.; GENNARI, S.M. et al. Toxoplasmosis in humans and animals in Brazil: high prevalence, high burden of disease, and epidemiology. Parasitology, v.139, n.11, p.1375-1424, 2012.

DUBEY, J.P. The history of Toxoplasma gondii - The first 100 years. Journal of Eukaryotic Microbiology, v.55, n.6, p.467-475, 2008.

DUBEY, J.P. Toxoplasmosis of animals and Humans. Boca Raton:CRC Press, 2010. 336 p.
GALISTEU, K.J.; MATTOS, C.B.; LELIS, A.G.L. et al. Prevalência e fatores de risco associados à toxoplasmose em grávidas e suas crianças no Noroeste Paulista, Brasil. Revista Panamericana de Infectologia, v.9, n.4, p.24-29, 2007.

GONTIJO DA SILVA M.; VINAUD M.C.; CASTRO A.M. Prevalence of toxoplasmosis in pregnant women and vertical transmission of Toxoplasma gondii in patients from basic units of health from Gurupi, Tocantins, Brazil, from 2012 to 2014. PLoS One, v. 10, n.11, 2015.

GUO, M.; DUBEY, J.P.; HILL, D. et al. Prevalence and risk factors for Toxoplasma gondii infection in meat animals and meat products destined for human consumption. Journal of food protection, v.78, n.2, p.457-476, 2015.

ISABEL, T.F.; COSTA, P.I.; SIMÕES, M.J.S. Toxoplasmose em gestantes de Araraquara/SP: análise da utilização do teste de avidez de IgG anti- Toxoplasma na rotina do pré-natal. Scientia Medica, v.2, n.7, p. 57-62, 2007

JONES, J.L.Toxoplasma gondii :Infection in the United States: Seroprevalence nd Risk Factors. American Journal Epidemiology, v.154, n.4, p. 357-365, 2001.

LOPES, F.M.R.; MITSUKA-BREGANÓ, R.; GONÇALVES, D.D. et al. Factors associated with seropositivity for antiToxoplasma gondii antibodies in pregnant women of Londrina, Paraná, Brazil. Memórias do Instituto Oswaldo Cruz, v.104, n.2, p.378-382, 2009.

MALMASI, A.; MOSALLANEJAD, B.; MOHEBALI, $M$. et al. Prevention of shedding and re-shedding of Toxoplasma gondii oocysts in experimentally infected cats treated with oral clindamycin: a preliminary study. Zoonoses and public health, v. $56, \mathrm{n}$. 2, p. 102-104, 2009. 
MITSUKA-BREGANÓ, R.; LOPES, F.M.R.; NAVARRO, T.I. Toxoplasmose adquirida na gestação e congênita: vigilância em saúde, diagnóstico, tratamento e condutas. Londrina: EDUEL, 2010. 64 p.

MOURA, D.S.; OLIVEIRA, R.C.M.; MATOS-ROCHA, T.J. Toxoplasmose gestacional: perfil epidemiológico e conhecimentos das gestantes atendidas na unidade básica de saúde de um município alagoano. Arquivos médicos dos Hospitais e da Faculdade de Ciências Médicas da Santa Casa de São Paulo, v.63, n.2, p.69-76, 2018.

MULLER, E.V.; TORQUETTI, J.D. Seropositivity prevalence of toxoplasmosis in pregnant women attended in a laboratory of the Paraná state coastal municipality. Revista Brasileira de Analises Clinicas (Rio de Janeiro), v.49, n.2, p.176-180, 2017.

NASCIMENTO, I.; CARVALHO, S.; CARDOZO, N. et al. Study of the prevalence of antibodies antiToxoplasma gondii in pregnant women in Bahia. Revista de Ciências Médicas e Biológicas, v.1, n.1, p.12-15, 2002.

NESI, $\quad \mathrm{V}$;; FELISBERTO, M.; GNUTZMANN, L. et al. Soroepidemiologia da infecção por Toxoplasma gondii em gestantes atendidas em um hospital público do oeste do Paraná. Revista da Escola de Saúde da Faculdade União de Goyazes, v.07, n.1, p.111-122, 2013.

Prefeitura Municipal de Curitiba. Secretaria Municipal da Saúde de Curitiba.. Pré-Natal, Parto, Puerpério e Atenção ao Recém-Nascido Programa Mãe Curitibana. Curitiba, PR, 2012.

QGIS Development Team. QGIS Geographic Information System [computer program]. Open Source Geospatial Foundation Project. 2018.
AMENDOEIRA, M.R.R; CAMILLOCOURA, L.F. Uma breve revisão sobre toxoplasmose na gestação. Scientia Medica, v.20, n.1, p.113-119, 2010.

SANTOS, A.F.; FERNANDES, T.; VRIESMANN, L.C.; Positivity rate of antibodies anti- Toxoplasma gondii in pregnant women from Curitiba-PR. Revista Saúde e Desenvolvimento, v.11, n.6, p.137-153, 2017.

SARTORI, A.L.T.; MINAMISAVA, R.; AVELINO, M.M. et al. Triagem pré-natal para toxoplasmose e fatores associados à soropositividade de gestantes em Goiânia, Goiás. Revista Brasileira de Ginecologia e Obstetricia, v.33, n.2, p.93-98, 2011.

SROKA, S.; BARTELHEIMER, N.; WINTER, A. et al. Prevalence and Risk Factors of Toxoplasmosis among Pregnant Women in Fortaleza, Northeastern Brazil. American Jounal Tropical Medicine and Hygiene, v.83, n.3, p.528-533. 2010.

TENTER, A.M.; HECKEROTH, A.R.; WEISS, L.M. et al.. Toxoplasma gondii: from animals to humans. International Journal Parasitology, v.30, n.12-13, p.1217-1258, 2000.

TENTER, A.M.Toxoplasma gondii in animals used for human consumption. Memórias do Instituto Oswaldo Cruz, v.104, n.2, p.364-369, 2009.

XAVIER, R.B.; JANNOTTI, C.B.; SILVA, K.S. et al. Risco reprodutivo e renda familiar: análise do perfil de gestantes. Ciência e Saúde Coletiva, v.18, n.4, p.1161-1171, 2013.

ZULPO, D.L; SAMMI A.S.; SANTOS J.R. et al. Toxoplasma gondii: a study of oocyst re-shedding in domestic cats. Veterinary parasitology, v. 249, p. 1720, 2018. 